\title{
PENGEMBANGAN KEWIRAUSAHAAN “KEMPLANG TUNU” SEBAGAI PRODUK CEMILAN KHAS KOTA PALEMBANG
}

\author{
Terttiaavini' $^{1}$, Luis Marnisah ${ }^{2)}$, Yosef Yulius ${ }^{3)}$, Tedy Setiawan Saputra ${ }^{4)}$ \\ 1) Sistem Informasi / Universitas Indo Global Mandiri \\ 2)Ekonomi Manajemen/Universitas Indo Global Mandiri \\ 3)Desain Komunikasi Visual / Universitas Indo Global Mandiri \\ 4)Magister Manajemen/Universitas Indo Global Mandiri \\ Jl. Jend. Sudirman No 629 KM 4.5 Palembang, Kode pos 30129 \\ Email : avini.saputra@uigm.ac.id ${ }^{11}$, luismarnisah@uigm.ac.id ${ }^{2)}$,yosef dkv@uigm.ac.id ${ }^{3)}$, \\ ttdyfaith@gmail.com ${ }^{4)}$
}

\begin{abstract}
ABSTRAK
Kemplang tunu merupakan salah satu produk cemilan khas masyarakat Sumatera Selatan yang sangat diminati. Kemplang tunu merupakan indutri rumahan yang jika digeluti dengan serius akan mendatangkan income yang signifikan. Usaha kemplang tunu masih jarang digeluti oleh masyarakat Palembang, karena market penjualan masih terbatas. Selain itu usaha kemplang belum begitu diminati, sehingga kalah bersaing dengan kuliner lainnya. Program pengabdian kepada masyarakat ini memiliki tiga fokus kegiatan, yaitu (1) meningkatkan kualitas dan brand image kemplang tunu menjadi salah satu cemilan khas kota palembang, (2) membangun kelompok usaha mandiri bagi masyarakat ekonomi lemah dengan 3) pelatihan memproduksi kemplang tunu. Kegiatan ini dapat membantu meningkatkan pendapatan keluarga dan menciptakan lapangan pekerjaan baru bagi ibu rumah tangga dan remaja yang di sekitar RT. 21 Kelurahan Ario kemuning Palembang.
\end{abstract}

Kata kunci : Kemplang tunu, Brand image, Kelompok usaha mandiri, Kelompok Non Produktif

\section{PENDAHULUAN}

Saat ini Kota Palembang telah menjadi salah satu tujuan wisata bagi turis lokal maupun mancanegara. Daya tarik kota Palembang terletak pada tempat wisata, kuliner, pekan olahraga, acara kebudayaan dll. Berbagai upaya dilakukan pemerintah untuk meningkatkan jumlah pengunjung, mulai dari perbaikan infrastruktur, perbaikan objek wisata, menyelenggarakan pentas budaya dan promosi kuliner. Saat ini, wisata kuliner belum menunjukkan peningkatan yang signifikan (Suherlan \& Hidayah, 2015). Hal ini akan cepat terwujud jika masyarakat turut serta berinovasi dan mempromosikan kuliner lokal Sumatera Selatan.

Kemplang artinya kerupuk, tunu artinya dipanggang. Jadi kemplang tunu berarti kerupuk yang dipanggang. Kemplang tunu merupakan salah satu cemilan khas masyarakat Sumatera Selatan yang sampai saat ini banyak diminati. Kemplang tunu secara turun temurun telah diproduksi dengan cita rasa dan teknik pembuatan yang khas. Harga jual kemplang tunu cukup terjangkau, sehingga setiap lapisan masyarakat dapat membeli kemplang tunu. Kemplang tunu dapat dijadikan sebagai makan ringan atau sebagai pengganti lauk pauk. Sampai saat ini kemplang tunu merupakan industri rumahan (home industry). Kuliner lokal merupakan cara terbaik untuk melihat warisan budaya tak benda sebuah destinasi adalah melalui konsumsi (Yurtseven \& Kaya, 2011). Pada dasarnya masyarakat Palembang merupakan masyarakat yang konsumtif terhadap kuliner lokal (anita, 2012), potensi wisata kuliner dapat mendukung pontensi pariwisata (Besra, 2012) sehingga dapat menunjang program visit to Palembang .

Saat ini kebutuhan hidup semakin tinggi, pendapatan yang diterima tidak lagi mencukupi standar hidup. Bagi masyarakat yang memiliki pendapatan dibawah standar, tentu sangat berat menjalani kehidupan sehari-hari. Oleh karena itu peran dosen di Perguruan tinggi sangat dibutuhkan untuk membantu menyelesaikan masalah. Cara yang dilakukan adalah memberdayakan masyarakat yang tidak produktif secara ekonomi/sosial menjadi produktif, dengan memberikan soft dan hard skill kepada warga sebagai bekal membuka peluang usaha baru. Adapun permasalah dari masing-masing target dijelaskan sebagai berikut : 
1) Permasalahan mitra saat ini

Target mitra adalah ibu rumah tangga dan remaja non produktif di sekitar RT. 21 RW 03 Kelurahan Ario Kemuning Kecamatan Kemuning Kota Palembang. Mereka termasuk dalam golongan masyarakat ekonomi lemah. Mereka memiliki pendapatan dibawah UMR (rendah). Mayoritas kepala keluarga berkerja sebagai pedagang/ buruh/ tukang parkir di pasar jaya Pal 5, yang letaknya \pm 500 meter dari tempat tinggal. Umumnya mereka adalah warga pendatang yang telah menetap bertahun-tahun dengan menyewa rumah di lokasi sekitar target mitra. Rata-rata memiliki tingkat pendidikan yang rendah SD atau SMP. Sulitnya mencari pekerjaan menyebabkan mereka tetap bertahan dengan pekerjaan tersebut. Berikut kondisi pemukiman disekitar tempat target mitra :
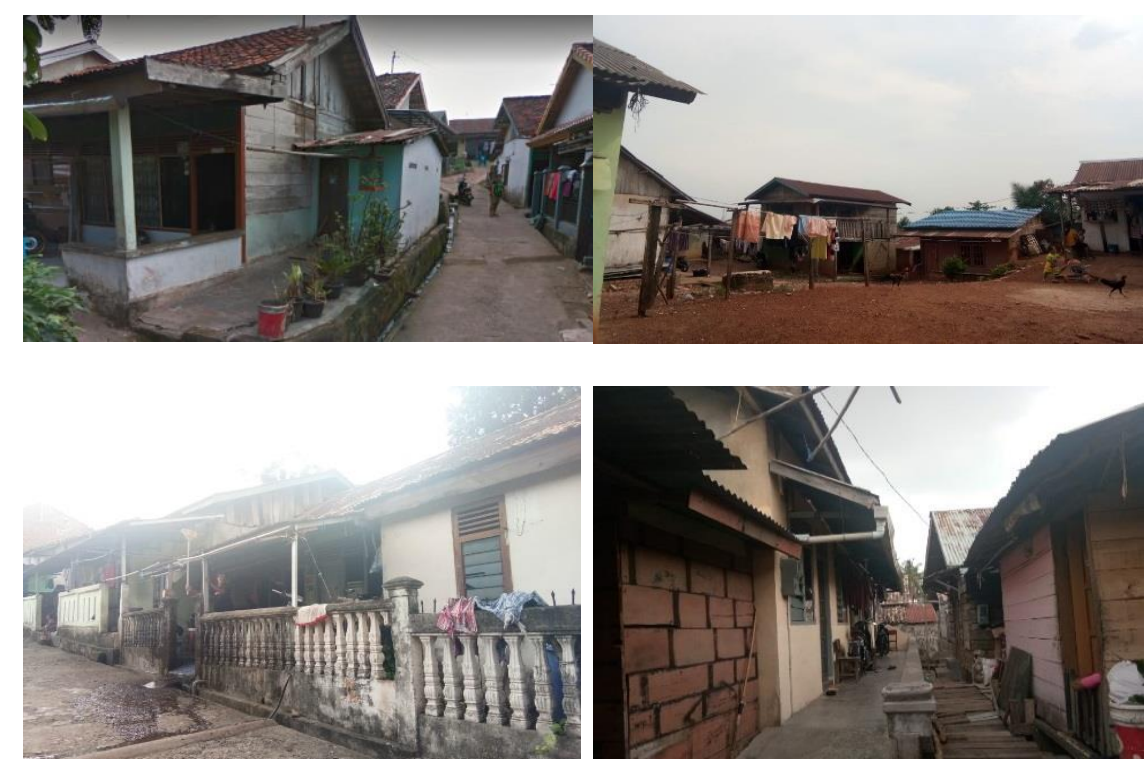

Gambar 1. Kondisi lingkungan target Mitra

Untuk mencukupi kebutuhan sehari-hari, istri/ibu-ibu bekerja dengan mencari upahan dari mengupas teri/cabe/bawang atau sebagai asisten rumah tangga. Paling tinggi upah yang diterima Rp.15.000/hari. Namun pekerjaan tersebut juga terbatas. Berikut adalah gambar beberapa gambar aktivitas ibu-ibu di daerah lingkungan target mitra :
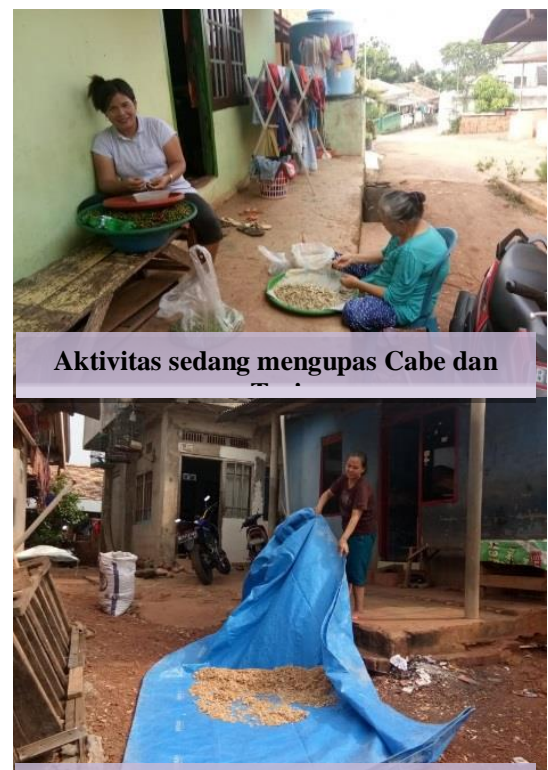

Aktivitas sedang menjemur teri

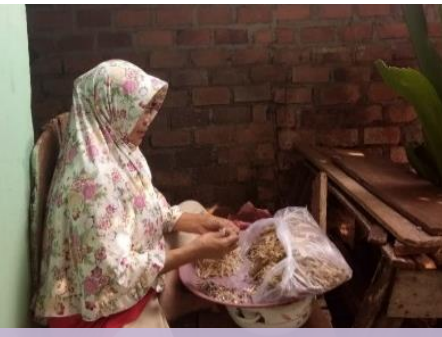

Aktivitas sedang mengupas Teri

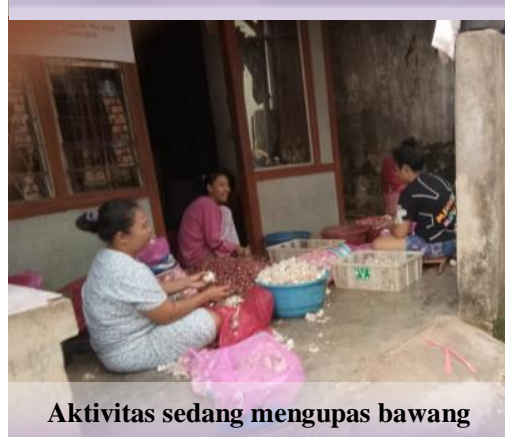

Aktivitas sedang mengupas bawang

Gambar 2. Aktifitas Ibu Rumah tangga sekitar lingkungan target mitra 
Tingginya kebutuhan hidup mempengaruhi kehidupan sosial. Rendahnya pendapatan keluarga berdampak pada banyak anak-anak yang putus sekolah, tingginya tingkat kriminalitas seperti menjual atau mengkonsumi ganja/ sabu-sabu/ menghirup lem aibon, prostitusi dan pencurian (Hardianto, 2009). Oleh karena itu perlu di cari solusi agar permasalahan dapat diatasi

Kemplang tunu merupakan warisan ragam kuliner masyarakat Sumatera Selatan. Saat ini kemplang tunu belum banyak di kenal oleh masyarakat luar. Kemplang tunu merupakan industri rumahan (home industry) yaitu unit-unit konsumtif dan produktif yang terdiri paling sedikit dua anggota rumah tangga yang sama-sama menanggung pekerjaan, makanan dan tempat berlindung (Kimbal, 2015).Bahan baku Kemplang tunu terbuat dari ikan sungai / ikan laut seperti tenggiri, gabus, sarden atau ikan sungai kecil yang dihaluskan, ditambah sagu, tepung, garam dan penyedap rasa. Sedangkan saus nya terdiri dari cabai, bawang merah gula dan garam. Tahap pertama pembuatan kemplang tunu adalah dengan membuat kemplang tunu mentah. Sebelum dipanggang kemplang tunu mentah dijemur terlebih dahulu agar tidak bantet. Proses pemanggangan cukup mudah, dengan menggunakan penjepit, kemplang tunu mentah di bolak-balik di atas arang sampai mengembang. Waktu panggang 1 lembar kemplang tunu \pm 15 detik. Selanjutnya dimasukkan kedalam kantong plastik siap untuk dipasarkan. Harga satu kantong kemplang tunu Rp. 15.000 / 40 pcs. Bahan baku pembuatan kemplang tunu banyak tersedia di pasar tradisional, sehingga untuk memproduksi kemplang tunu tidak mengalami kesulitan.

Permasalahannya adalah kemplang tunu belum banyak dikenal oleh masyarakat luar Sumatera Selatan, sehingga berdampak pada peningkatan omset penjualan yang tidak signifikan. Tim pengabdian melakukan observasi untuk mengetahui faktor yang mempengaruhi kondisi tersebut. Dari hasil observasi dapat disimpulkan bahwa :

a. Centra penjualan tidak strategis. Kawasan penjualan kemplang tunu berada di Jl. Pipa reja kelurahan Kemuning Palembang. Lokasi tersebut bukan berada di jalan utama (tidak strategis). Jarang dilewati oleh masyarakat luar kota Palembang sehingga produk kurang dikenal (Fitriah \& Hendro, 2017).
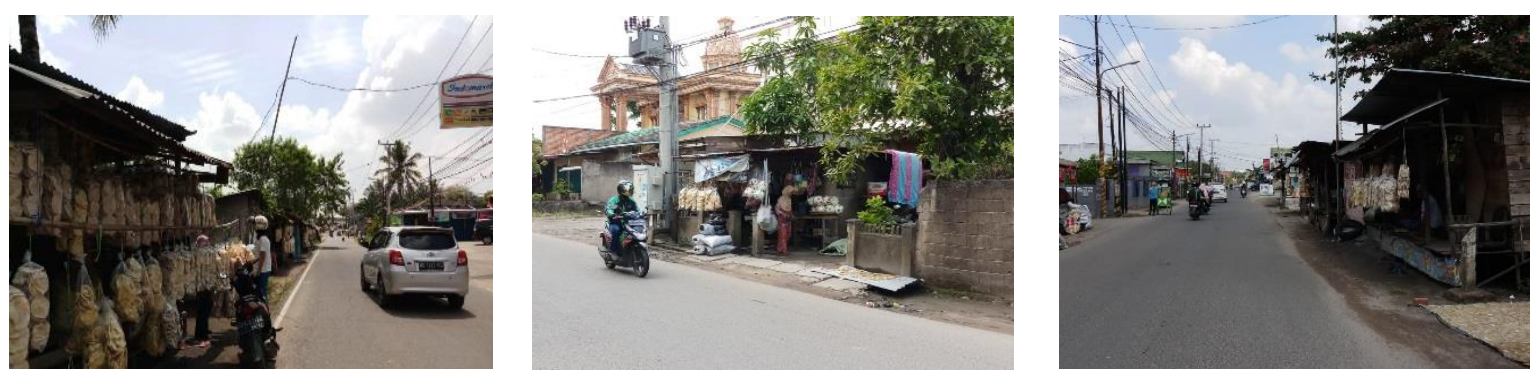

Gambar 3. Centra penjualan kemplang tunu Jl. Pipa Reja kelurahan Kemuning Palembang

b. Proses pemanggangan kemplang tunu. Usaha kemplang tunu temasuk dalam katagori industri rumahan. Tersedia kemplang tunu mentah yang dapat dipesan dari daerah Ogan ilir (OI). Sebelum dipanggang, kemplang tunu dijemur terlebih dahulu. Proses penjemuran sangat tidak higienis, mereka menjemur kemplang tunu dipinggir jalan yang terkontaminasi dengan debu (gambar 4a, 4b). Proses pemangangan juga masih menggunakan cara konvensional dan juga kurang higienis (gambar 4c) (Fitriah \& Hendro, 2017). Dibawah ini foto proses pemanggangan dan penjemuran kemplang tunu.

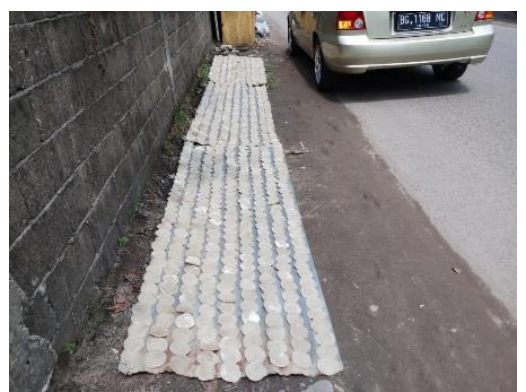

(a) Proses penjemuran

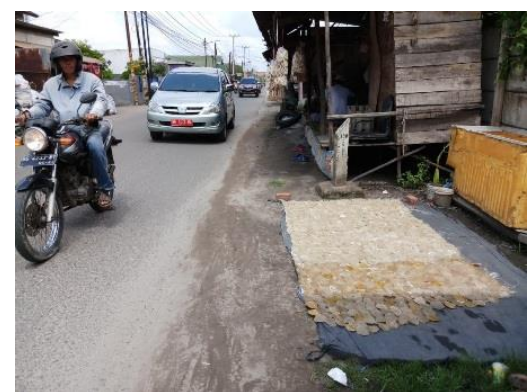

(b) Proses penjemuran 


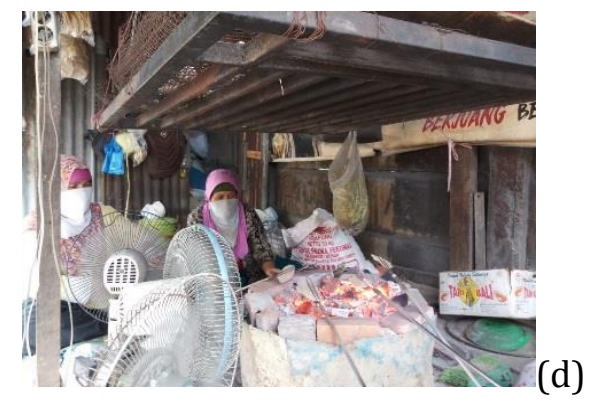

Proses pemanggangan

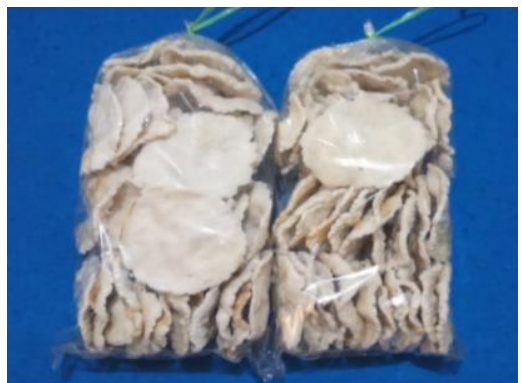

e) Kemasan Kemplang Tunu

Gambar 4. Proses pemanggangan dan penjemuran kemplang tunu.

c. Packaging shape (bentuk Kemasan). Bentuk dan tampilan kemasan sangat sederhana, yaitu hanya dimasukkan kedalam kantong putih yang ujungnya diikat dengan tali plastik. Kemas juga tidak memiliki label sehingga nilai jualnya rendah (Gambar 5e)

Dari penjelasan diatas maka dapat disimpulkan bahwa permasalahan yang dihadapi mitra dapat diselesaikan dalam kegiatan pengabdian ini. Solusi dari permasalahan tersebut adalah membanggun usaha kemplang tunu ditempat target mitra sehingga menjadi centra produksi kemplang tunu yang inovatif agar dapat meningkatkan penghasilan warga sekitar (Alimudin, A., \& Yoga, 2015). Selain itu letak usaha yang strategis (tengah kota) akan mempermudah proses distribusi penjualan kemplang tunu.

\subsection{Tujuan Program Pengabdian Kepada masyarakat}

Tujuan dari program pengabdian ini adalah menjawab dari permasalahan yang diuraikan pada latar belakang, yaitu membangun star up usaha kemplang tunu dengan memberikan pelatihan, praktek dan latihan bagi ibu-ibu dan remaja non produktif rumah tangga dengan memproduksi kemplang tunu yang memiliki standar produksi, kualitas yang baik dan bentuk kemasan yang menarik, sehingga dapat bersaing dengan produk cemilan khas palembang lainnya.

\subsection{Manfaat Program Pengabdian kepada masyarakat}

Adapun manfaat dari program pengabdian kepada masyarakat ini adalah

1. Meningkatkan pengetahuan ibu rumah tangga dalam memproduksi kemplang tunu.

2. Membangun Star up centra kemlpang tunu

\section{METODE PELAKSANAAN PENGABDIAN}

Kegiatan pengabdian kepada masyarakat terdiri dari beberapa tahapan. Tahapan dijelaskan sebagai berikut

\subsection{Tahapan pelaksanaan kegiatan pengabdian}

Tahapan dalam pelaksanaan kegiatan pengabdian terdiri dari beberapa kegiatan ditampilkan dalam diagram dibawah ini :

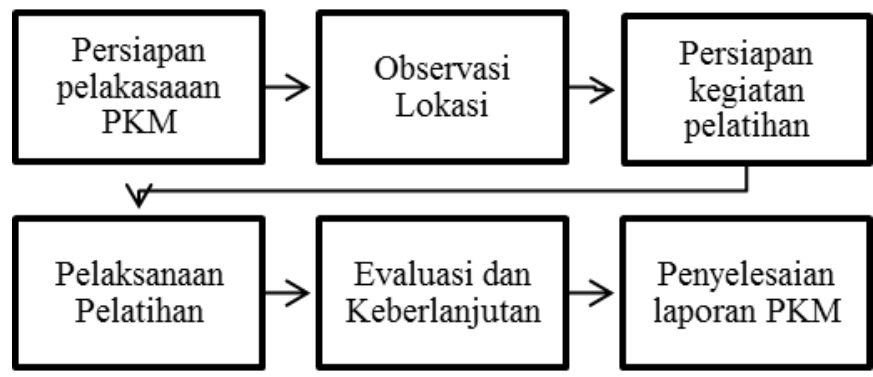

Gambar 6. Tahapan pelaksanaan PKM 


\subsection{Persiapan kegiatan Pelatihan}

Persiapan adalah segala bentuk perlengkapan, perencanaan, usaha yang dilakukan kelompok/individu untuk mempersiapkan diri melakasanakan kegiatan PkM. Pada tahap ini yang dilakukan adalah

1) Menetapkan dan menghubungi narasumber. Narasumber diberikan arahan tentang sasaran yang akan dicapai. Nara sumber yang terlibat adalah

1. Pelatihan membuat adonan kemplang tunu dan teknik pemanggangan kemplang tunu nara sumber Ibu Nur Azizah.

2. Pelatihan pencatatan administrasi penjualan kemplang tunu (pembukuan) nara sumber Ibu Dr. Luis Marnisah, MM

3. Pelatihan tentang pengenalan bentuk Packaging shape (bentuk kemasan) dan merancang logo yang menarik untuk meningkatkan brand image kemplang tunu nara sumber Bpk. Yosef Yulius, S.Sn., M.Sn.

4. Sosialisasi tentang pengurusan izin usaha, nara sumber Bpk. Tedy Setiawan Saputra, SE, MM.

2) Tim pengabdian menyiapkan seluruh keperluan pelatihan, seperti menyiapkan media presentasi, menyiapkan alat penggiling ikan dan alat pelengkap produksi lainnya, menyiapkan alat presentasi, menghubungi peserta, dan membeli keperluan lainnya.

\subsection{Obeservasi Lokasi}

Pada saat proposal ini diajukan, tim pengabdian telah mendapatkan persetujuan untuk melaksanakan kegiatan pengabdian di lokasi mitra. Jadwal pelaksanaan kegiatan PkM tersebut pada Tanggal 04 dan 08 Agustus 2019 di Jl. Rimba Kemuning No 33 RT. 21 Lrg Amal Kel. Ario Kemuning Palembang, Tuan Rumah : Ibu Mardiana (Ketua kelompok PkM).

\subsection{Pelaksanaan pelatihan} yaitu

Inti kegiatan pengabdian berada pada tahap ini, yaitu memberikan 4 macam pelatihan pada mitra,

1) Pelatihan pembuatan kemplang tunu;

\begin{tabular}{lll}
\hline \multicolumn{1}{c}{$\begin{array}{c}\text { Tanggal } \\
\text { kegiatan }\end{array}$} & $:$ & \multicolumn{1}{c}{ 04 Agustus 2019} \\
\hline $\begin{array}{l}\text { Tujuan } \\
\text { Peran mitra }\end{array}$ & $:$ & Memberikan pelatihan tentang cara membuat kemplang tunu \\
\hline Materi & $:$ & $\begin{array}{l}\text { Teknik memilih ikan berkualitas baik, cara membuat kemplang } \\
\text { tunu dari proses membuat adonan sampai pembungkusan }\end{array}$ \\
\hline Narasumber & $:$ & $\begin{array}{l}\text { Ibu Nur Azizah ( Pengusaha kemplang tunu sejak } \\
\text { tahun 2008. }\end{array}$ \\
\hline $\begin{array}{l}\text { Teknik } \\
\text { pelatihan }\end{array}$ & $:$ & Pemaparan materi dan Praktek langsung \\
\hline $\begin{array}{l}\text { Bahan praktek } \\
\text { Lama pelatihan }\end{array}$ & $:$ & Ikan, bumbu, air, wadah plastik dll, Fc. Bahan pelatihan \\
\hline $\begin{array}{l}\text { Indikator } \\
\text { keberhasilan }\end{array}$ & $:$ & Peserta dapat membuat kemplang tunu \\
\hline
\end{tabular}

a) Bahan -bahan yang digunakan dalam pembuatan kemplang tunu

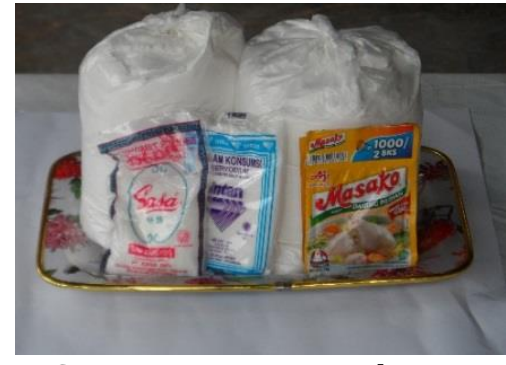

a. Sagu, garam, Penyedap rasa

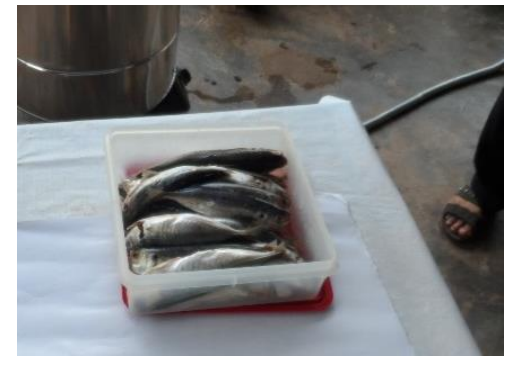

b. Ikan sarden segar 


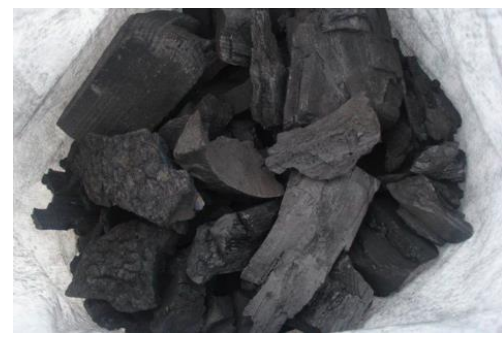

c. Arang

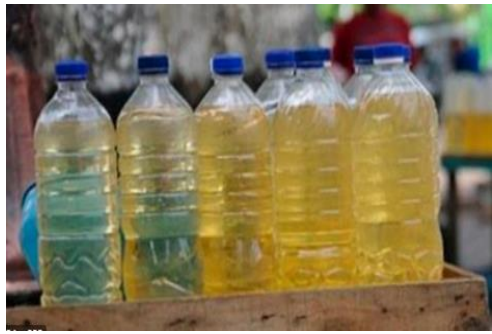

d. Bensin

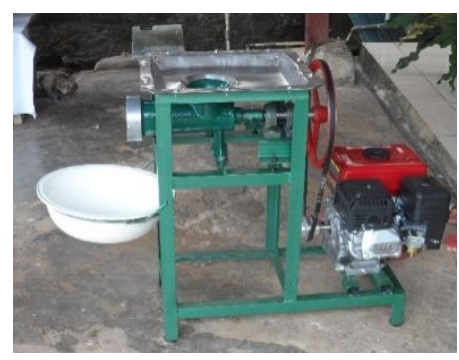

a. Alat penggiling Ikan

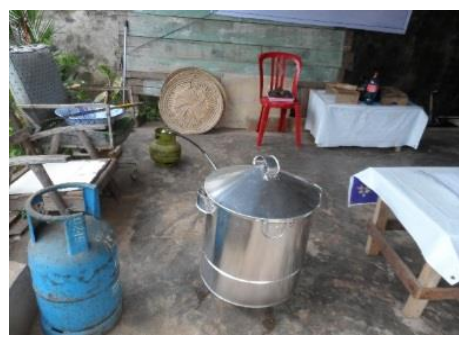

d. Alat pengukus dan Tabung gas

b) Peralatan yang digunakan :

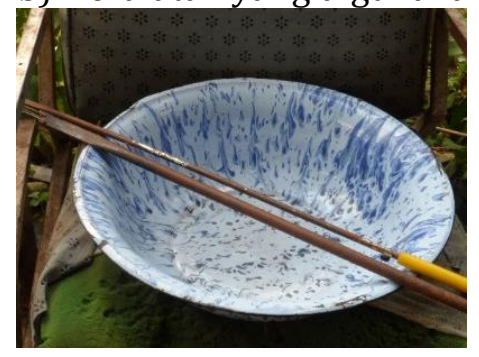

b. Baskom dan alat pemanggang

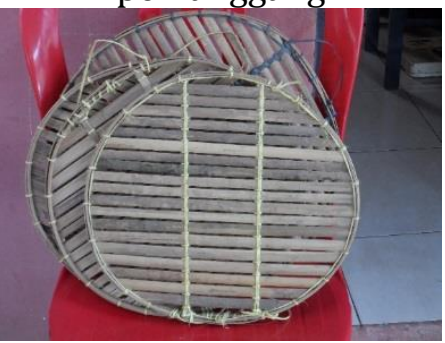

e. tampah Rotan

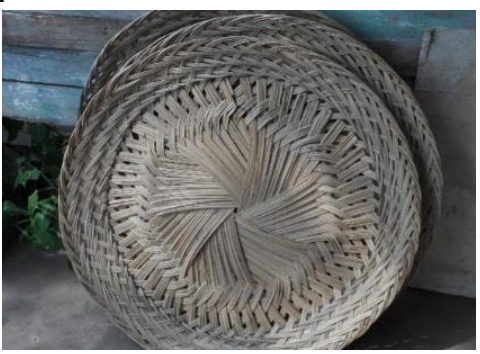

c. Tampah Rajut

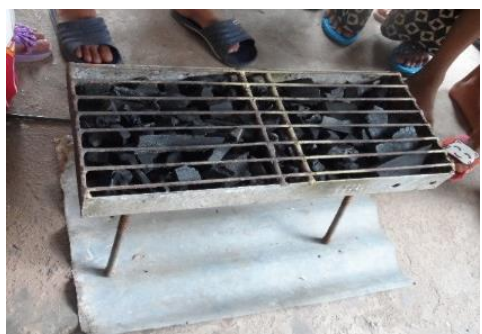

f. Alat pemanggang kemplang

Tunu

Gambar 7. Peralatan Produksi kemplang Tunu

c) Cara Pembuatan :

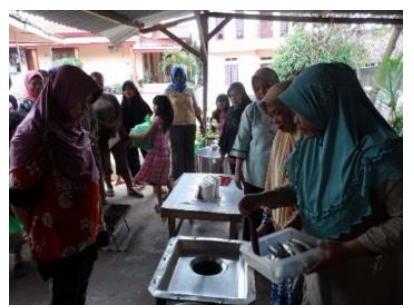

1. Ikan segar (sarden) digiling dengan menggunakan alat penggiling sampai halus. Biasanya 2 (dua) kali penggilingan ikan sudah halus dan siap digunakan untuk proses selanjutnya

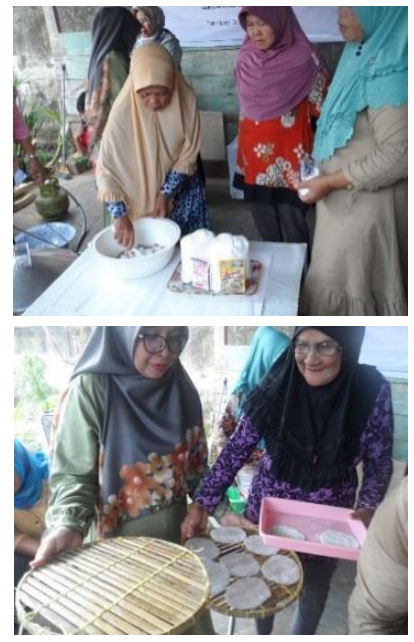

2. Pemberian garam dan penyedap rasa supaya merata masukkan kedalam mangkok kecil diberi air, dan aduk hingga rata, selanjutnya baru dimasukkan ke dalam adonan

3. Ratakan dengan alat penggilas sampe berbentuk gepeng dan bulat

4. Latakkan diatas nipah. Sebelumnya nipah diberi minyak agar tidak lengket. 

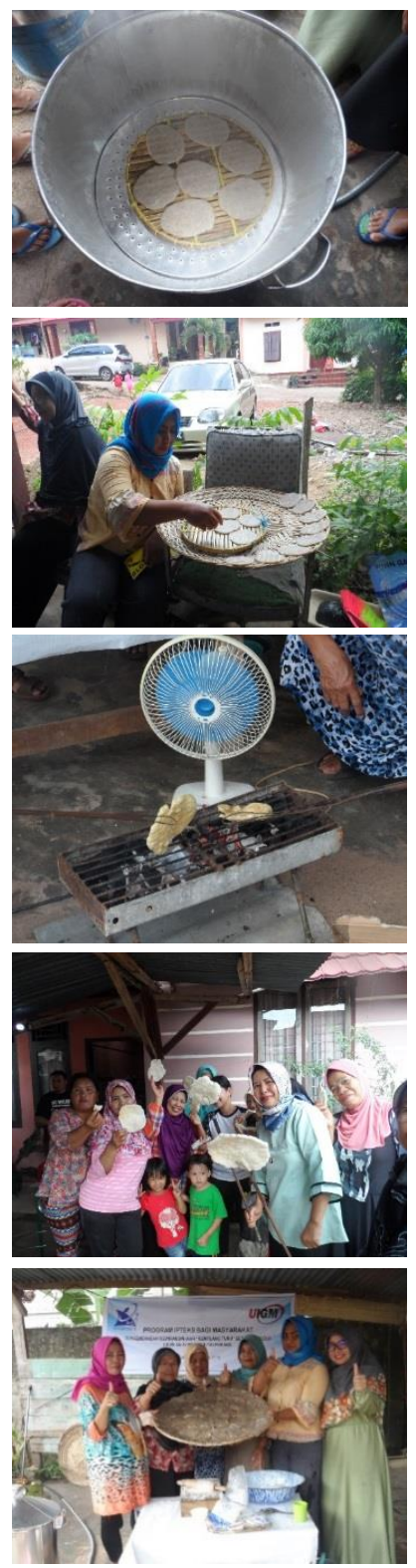

5. Lalu dikukus selama \pm 5 menit. Lalu angkat

6. Letakkan hasil kukusan diatas nipah lebar, sampai penuh.

7. Lalu dijemur selama 1-2 hari penuh.

8. Kemudian Kemplang tunu mentah dipanggang diatas arang \pm 5 menit. Kemplang tunu akan mengembang.

9. Hasil pemanggangan dapat dinikmati oleh peserta pelatihan

10. Gambar disebelah adalah tim pembuat kemplang tunu dan ketua pelaksana PkM

Gambar 8. Proses produksi Kemplang Tunu

2) Memberikan pelatihan pencatatan administrasi penjualan kemplang tunu (pembukuan).

\begin{tabular}{lcl}
\hline \multicolumn{1}{c}{ Tanggal kegiatan } & $:$ & \multicolumn{1}{c}{ 08 Agustus 2019} \\
\hline Tujuan & $:$ & Memberikan pelatihan tentang pembukuan sederhana \\
\hline Peran mitra & $:$ & Sebagai peserta pelatihan \\
\hline Materi & $:$ & $\begin{array}{l}\text { Menghitung harga pokok penjualan (modal) dan membuat } \\
\text { perhitungan laporan rugi laba }\end{array}$ \\
Narasumber & $:$ & $\begin{array}{l}\text { Dr. Drs. Luis Marnisah, MM (Dosen Prodi. Ilmu Manajemen } \\
\text { sebagai anggota 1) }\end{array}$ \\
Teknik pelatihan & $:$ & Pemaparan materi dan latihan \\
Bahan praktek & $:$ & Map plastik, pena, Note book, Fc. Bahan pelatihan \\
Lama pelatihan & $:$ & 4 jam ( selama 1 hari ) \\
Indikator & $:$ & Peserta dapat membuat pembukuan sederhana \\
keberhasilan & &
\end{tabular}

3) Pelatihan tentang pengenalan bentuk Packaging shape (bentuk kemasan) dan merancang logo yang menarik untuk meningkatkan brand image kemplang tunu; 


\begin{tabular}{lcl}
\hline \multicolumn{1}{c}{ Tanggal kegiatan } & $:$ & \multicolumn{1}{c}{ 08 Agustus 2019 } \\
\hline Tujuan & $: \begin{array}{l}\text { Memberikan sosialisasi tentang dampak penggunaan nama } \\
\text { produk (brand image) dan pemilihan bentuk kemasan } \\
\text { (Packaging shape) dan HaKI }\end{array}$ \\
\hline Peran mitra & $:$ Sebagai peserta \\
\hline Materi & $: \begin{array}{l}\text { Pengetahuan tentang teknik membuat logo, merek dan } \\
\text { Packaging shape, HaKI }\end{array}$ \\
\hline Narasumber & $: \begin{array}{l}\text { Bpk. Yosep Yulius, M.Sn (Dosen Prodi. Desain visual grafis } \\
\text { sebagai anggota 2). }\end{array}$ \\
\hline Teknik pelatihan & $:$ Pemaparan materi dan tanya jawab \\
\hline Bahan praktek & $:$ Fc. Bahan sosialisasi \\
\hline $\begin{array}{l}\text { Lama pelatihan } \\
\text { Indikator }\end{array}$ & $:$ 3 jam (selama 1 hari) \\
keberhasilan & $:$ & $\begin{array}{l}\text { Peserta memahami pentingnya nama merek (brand image) } \\
\text { dan bentuk kemasan (packaging shape) }\end{array}$ \\
\hline
\end{tabular}

4) Sosialisasi tentang pengurusan izin usaha

\begin{tabular}{lcl}
\hline \multicolumn{1}{c}{ Tanggal kegiatan } & $:$ & \multicolumn{1}{c}{ 08 Agustus 2019 } \\
\hline Tujuan & $:$ Memberikan sosialisasi tentang cara mengurus izin usaha \\
Peran mitra & $:$ Sebagai peserta \\
Materi & $:$ Langkah-langkah dan syarat pengurusan SIUP, SITU, izin \\
& kesehatan (BPOM) dan sertifikat halal \\
Narasumber & $:$ Bpk. Tedy Setiawan Saputra, SE., MM \\
Teknik pelatihan & $:$ Pemaparan materi dan tanya jawab \\
Bahan praktek & $:$ Fc. Bahan sosialisasi \\
Lama pelatihan & $:$ & 3 jam (selama 1 hari) \\
Indikator & $:$ & Peserta memahami cara mengurus surat izin \\
keberhasilan & &
\end{tabular}

Berikut gambar pada saat kegiatan :

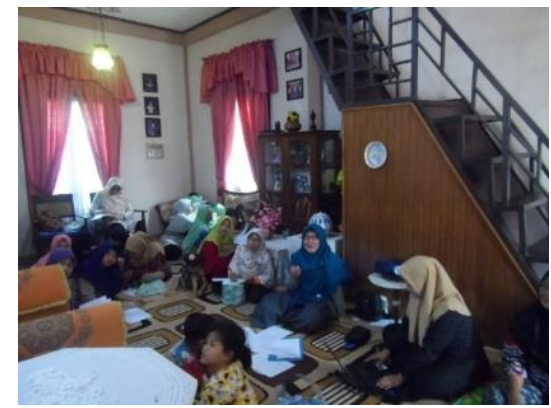

Gambar 9.

Pemateri ke dua

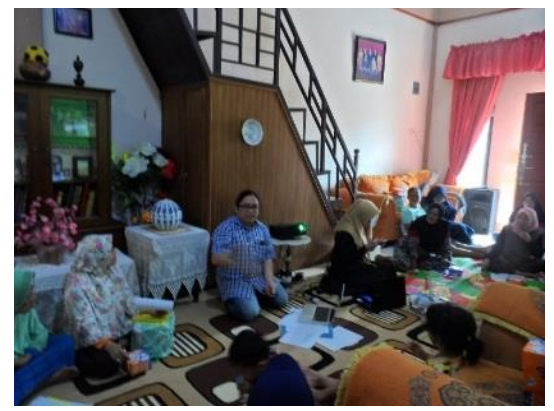

Gambar 10.

Pemateri ke tiga

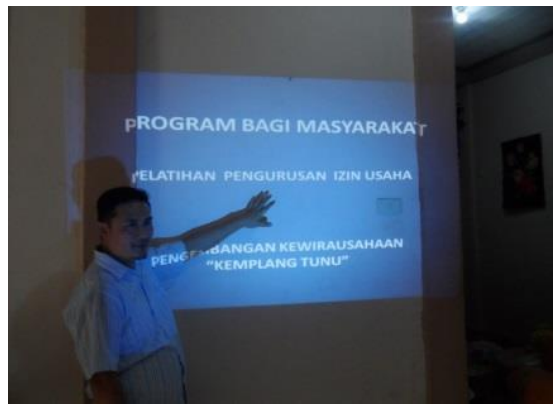

Gambar 11.

Pemateri ke Empat

\subsection{Produk kemasan yang dihasilkan}

Berikut adalah contoh produk yang di design untuk packaging shape kemplang tunu, yaitu

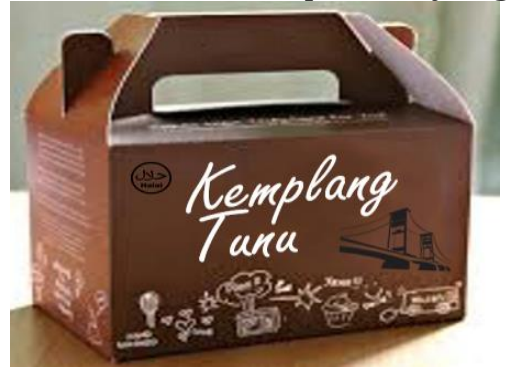

Kemasan pada gambar 12 dirancang untuk kapasitas 40 pcs dan 30pcs. Menggunakan bahan karton berwarna coklat dengan ketebalan $2 \mathrm{~mm}$.

Keunggulan : Desain lebih modern dan kreatif, dapat langsung dibawa dan terlindung dari benturan.

Gambar 12. Kemasan untuk kapasitas

30 pcs dan 40 pcs 


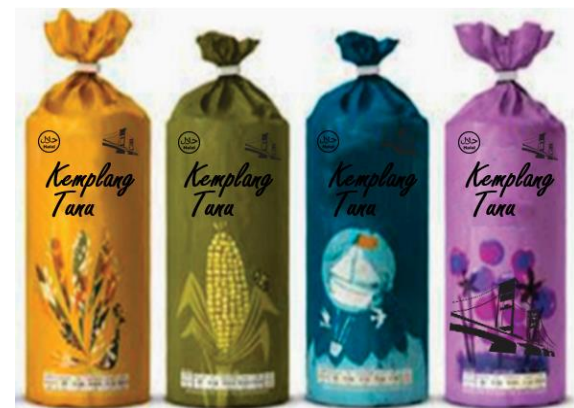

Gambar 13. Kemasan untuk kapasitas 20 pcs
Kemasan pada gambar 13 merupakan kemasan untuk kapasitas 20 pcs. Berbentuk seperti tabung dan diberi klip diatasnya. Didalam kemasan diberi lapisan plastik menjaga agar kemplang tunu tetap utuh jika kena benturan.

Kemasan ini dirancang untuk dikonsumsi di perjalanan. Klip plastik dapat dibuka dan ditutup kembali, agar tekstur kemplang tunu tetap renyah.

Kunggulan : Desain lebih berwarna dan menarik, ukuran lebih kecil sehingga dapat dimasukkan kedalam tas.

\subsection{Evaluasi pelaksaanaan program pengabdian}

Evaluasi pelaksanaan dan keberlanjutan program dilakukan setelah kegiatan PKM selesai dilaksanakan, dengan cara membagikan kuesioner sebelum dan sesudah pelatihan. Untuk menentukan efektifitas program, Metode analisa yang digunakan menggunakan model evaluasi program Kirkpatrick yang terdiri dari empat tahap yaitu Reaction (Reaksi), Learning (Belajar), Behavior (Tingkah laku), Results (Hasil) (Kirkpatrick, 2006). Hasil dari analisa data yaitu pada level 1 : nilai 84\% , berarti Pelatihan memberikan reaksi positif yang tinggi kepada peserta pelatihan, level 2 : nilai $54,29 \%$, berarti Hasil pelatihan menunjukkan bahwa peserta bereaksi positif karena menyadari mendapat masukan yang berguna selama pelatihan, level 3 : nilai 85,19\% berarti Pelatihan memberikan reaksi positif yang tinggi kepada peserta pelatihan

\section{HASIL DAN PEMBAHASAN}

\subsection{Keberlanjutan program}

a) Tindak lanjut hasil evaluasi

Evaluasi pelaksanaan program menjadi dasar untuk melakukan perbaikan. Tim pengabdian dapat memberikan kembali pelatihan yang kurang dipahami oleh peserta, karena tujuan dari kegiatan pengabdian ini adalah membentuk kelompok usaha mandiri. Agar kegiatan ini dapat memberikan manfaat yang maksimal bagi masyarakat, maka ketua pengabdi menyerahkan seluruh peralatan pembuatan kemplang tunu kepada ketua kelompok Ibu RT 21, yaitu Ibu. Mardiana.

b) Perluasan market penjualan

Ruang lingkup kegiatan pengabdian tidak membahas tentang market penjualan. Rencana penjualan kemplang tunu akan dilakukan secara (1) Konvensional yaitu dititip kebeberapa toko (2) Online yaitu melalui aplikasi penjualan produk UMKM atau melalui media sosial yang lagi trend saat ini. Kegiatan pemasaran ini dapat dilakukan oleh kelompok PkM itu sendiri atau dengan orang lain. Perhitungan untung untuk tahap pemasaran ini akan dihitung kemudian

c) Inovasi produk

Produk kemplang tunu saat ini memiliki satu varian (rasa asin). Untuk inovasi produk dapat dilakukan percobaan untuk beberapa rasa dan warna. Namun pada tahap awal, pengembangan produk ini belum dilakukan, karena harus dilakukan uji coba rasa terlebih dahulu pada beberapa responden. Jika banyak yang menyetujui, maka produk varian ini akan diproduksi dan dipasarkan.

\section{KESIMPULAN}

Dari kegiatan yang telah dilakukan, maka dapat disimpulkan bahwa

1. Kegiatan PkM pengembagan usaha Kemplang tunu memberikan dampak positif bagi bagi Ibu rumah tangga RT. 21 kel. Ario Kemuning untuk meningkatkan kemampuan dalam memproduksi kemplang tunu.

2. Usaha kemplang tunu merupakan star up bagi warga RT. 21, kegiatan ini menumbuhkan niat untuk membangun usaha baru yang merupakan kelanjutan atau mendukung usaha kemplang tunu.

3. Kemplang tunu merupakan usaha industri rumahan, namun hasilnya dapat dijadikan produk khas kota Palembang seperti pempek, songket, kerajinan laker yang sudah lebih dulu dikenal. 


\section{UCAPAN TERIMA KASIH}

Ucapan terimakasih kepada Ketua RT. 21, Ibu - ibu dan Remaja RT. 21 Ario Kemuning, Ibu Mardiana (peneyedia Tempat PkM), Universitas Indo Global Mandiri dan Direktorat Riset dan Pengabdian Masyarakat Direktorat Jenderal Penguatan Riset dan Pengembangan Kementrain Riset, Teknologi dan Pendidikan Tinggi sebagai pemberi dana Hibah PkM

\section{DAFTAR PUSTAKA}

Anita, Sumarni bayu. 2012. Kuliner dan Kinstruksi Identitas kelokalan studi kasus tentang pempek bagi "wong Kito" di kota Palembang. Tesis. Universtas Gajah mada.Perpustakaan Pusat UGM

Alimudin, A., \& Yoga, H. 2015. Strategi Meningkatkan Loyalitas Pelanggan Pada Usaha Kecil Produk Makanan Ringan Di Surabaya. Sustainable Competitive Advantage (SCA), 5(1), 1-12.

Besra, E. (2012). Potensi Wisata Kuliner Dalam Mendukung Pariwisata Di Kota Padang.

Jurnal Riset Akuntansi Dan Bisnis, 12(1), 74-101. Retrieved from http://jurnal.umsu.ac.id/index.php/akuntan/article/downloadSuppFile/402/26

Fitriah, W., \& Hendro, O. 2017. Tinjauan Usaha Krupuk Kemplang Ikan Bilik Desa Lumpatan, 1(2), 115123. Retrieved from http://ejournal.uigm.ac.id/index.php/PGM/article/view/413/502

Hardianto, F. N. 2009. Analisis Faktor-Faktor Yang Mempengaruhi Tingkat Kriminalitas Di Indonesia Dari Pendekatan Ekonomi. Bina Ekonomi, 13(2), 28-41. Retrieved from http://journal.unpar.ac.id/index.php/BinaEkonomi/article/view/713/697

Kimbal, R.W. 2015. Modal Sosial Dan Ekonomi Industri Kecil Sebuah Studi Kualitatif.Penerbit : Depublish, Yogyakarta.

Kirkpatrick, D.L., Kirkpatrick, J.D., 2006. Evaluating Training Program; The Four Levels, 3rd Edition. San Fransisco: Berrett Koehler, Inc.

Suherlan, H., \& Hidayah, N. 2015. Sikap wisatawan nusantara terhadap produk wisata kuliner di Kota Palembang. Jurnal Ilmiah Pariwisata, 20(2), e147-e160. Retrieved from http://stpbandung.net/bitstream/handle/123456789/235/Sikap wisatawan nusatara terhadap produk wisata kuliner di kota Palembang.pdf?sequence=1\&isAllowed=y

Yurtseven, H. R., \& Kaya, O. 2011. Local food in local menus: The case of Gokceada. Tourismos, 6(2), 263-275. https://doi.org/10.1007/JHEP07(2012)019 